dacryoadenitis (26 patients) and myositis (3 patients). Patients with orbital mass (group 1) and dacryoadenitis (group 2) were included into further investigation. Results: Patients in group 1 had systemic disease in $51,1 \%$ compared to $7,7 \%$ in group 2. Patients with orbital mass presented with more severe clinical manifestations, including significant exophthalmos $(82,2 \%)$, periorbital oedema $(95,5 \%)$ and hyperemia $(46,7 \%)$, strabismus $(31,1 \%)$, globe movement restriction $(71,1 \%)$, chemosis $(8,9 \%)$. Orbital mass was accompanied by necrotizing scleritis in 7 and PUK in 6 patients. Symptoms included orbital pain $(88,9 \%)$ and binocular diplopia $(73,3 \%)$. BCVA in this group was 0.67 . Clinical outcome was relatively unfavourable: in $24,4 \%$ BCVA was less than 0.3 , in 5 patients enucleation was performed, in $24,4 \%$ strabismus developed and in $73,3 \%$ globe movement restriction occurred. Clinical course and outcome were significantly more favourable in patients with dacryoadenitis. Periorbital oedema, exophthalmos and chemosis did not show significant difference in groups, though orbital pain, binocular diplopia, globe movement restriction, strabismus, optic neuropathy, necrotizing scleritis, PUK were observed in group1 significantly more often. Clinical outcome in group 2 was much more favourable with no cases of enucleation and persistent visual loss. They only had moderate exophthalmos $1-3 \mathrm{~mm}(65,4 \%)$, strabismus $(7,7 \%)$ and mild globe movement restriction $(19,2 \%)$

Conclusions: Three types of orbital involvement in GPA were proposed: orbital mass, dacryoadenitis and myositis. Patients with orbital mass are characterised more often with systemic disease, more severe clinical course not uncommon associated with other ocular manifestations (necrotizing scleritis, PUK, orbital walls destruction), relatively unfavourable outcome with high level of morbidity (optic nerve atrophy, anophthalmos, strabismus) and higher rate of recurrences. Disclosure of Interest: None declared

DOI: 10.1136/annrheumdis-2018-eular.5571

\section{AB0659 PREVALENCE AND CLINICAL FEATURES OF CRANIAL AND EXTRACRANIAL GIANT CELL ARTERITIS}

E. Fernández ${ }^{1}$, I. Monjo ${ }^{1}$, L. Coronel ${ }^{2}$, D. Benavent ${ }^{1}$, A. Balsa ${ }^{1}$, E. De Miguel ${ }^{1}$. ${ }^{1}$ Rheumatology, Hospital Universitario La Paz, Madrid; ${ }^{2}$ Rheumatology, Hospital Universitario Nuestra Señora de La Candelaria, Santa Cruz de Tenerife, Spain

Background: Giant cell arteritis (GCA) is the most common systemic vasculitis in adults. Although it typically affects the cranial branches derived from the aortic arch, there is increasing evidence of the damage occurring to large vessel extracranial arteries, which is usually misdiagnosed. This subset of large vessel extracranial GCA may have specific clinical features that could hinder the diagnosis, which highlights the need for a different treatment and follow up.

Objectives: To analyse the frequency and clinical and analytical features in cranial and extra-cranial GCA.

Methods: An observational retrospective descriptive study analysing data from patients with GCA was performed in our hospital. Colour duplex sonography (CDS) studies carried out in the last 29 months were revised. Standardised CDS images from the frontal and parietal branches of the temporal superficial artery (TA) and axillary artery (AXE) with GCA compatible image with intra or extra-cranial involvement (hypoechoic, homogeneous and circumferential thickening of the artery wall $\geq 0.34 \mathrm{~mm}$ in $\mathrm{TA}$, and $\geq 1 \mathrm{~mm}$ in AXE, respectively). SPSS version 23 were used to analyse a total of 29 variables.

Results: Out of the 119 patients that were tested in our fast track GCA clinic, with standardised CDS of TA and AXE, 22 had GCA. All GCA patients was hallo sign in CDS. From them, 7 had large vessel involvement (31.8\%), from whom 6 were mixed and 1 had exclusively extra-cranial involvement. Mean age at diagnosis was $76 \pm 9.7$ SD in the extracranial GCA arteritis and $79 \pm 5.7$ SD in the cranial GCA. The extracranial subset had a greater number of men than the cranial (28.6\% and $26.6 \%$, respectively) and suffered usually more fever $(28.5 \%>6.6 \%$, respectively), constitutional syndrome $(85.7 \%>40 \%$, respectively) or polymyalgia rheumatica $(42.8 \%>40 \%$, respectively). However, they suffered with more frequency from headache ( $85.7 \%$ vs $93.3 \%$ ) and jaw claudication ( $28.5 \%$ vs $33.3 \%$ ). None of them suffered from visual impairment or central nervous system involvement; both do appeared in the cranial GCA group in $13.3 \%$ and $6.6 \%$. In the blood tests, mean \pm standard deviation was: ESR $87.6 \pm 36 \mathrm{~mm} / \mathrm{h}$ in cranial GCA and 89.5 $\pm 19.5 \mathrm{SD} \mathrm{mm} / \mathrm{h}$ in extracranial GCA, CRP $65 \pm 57.6$ and $82.6 \pm 48.4 \mathrm{mg} / \mathrm{L}$ and $\mathrm{Hb} 11.4 \pm 1.3$ and $12.1 \pm 1.3 \mathrm{~g} / \mathrm{dl}$, respectively. Patients with large vessel involvement met ACR criteria in $80 \%$ opposite $92.8 \%$ from these with solely cranial GCA. AT biopsy was performed in 7 patients in the cranial subset and 2 in the extra-cranial, testing positive for GCA in $5(71.4 \%)$ in the first group, and none in the second one. CT-PET was performed in 2 patients with cranial GCA with negative results, and in 4 with large vessel involvement, testing positive in $50 \%$. Despite the large differences, the statistical analysis didn't reach statistical significance due to the small simple size.

Conclusions: One third of the patients in our study had large vessel involvement, making axillary vessel CDS an important tool for the clinical exam of this disease. These patients tend to be younger and start more often with fever or general syndrome and less with GCA typical symptoms like headache, jaw claudication or visual loss.

Disclosure of Interest: None declared

DOI: 10.1136/annrheumdis-2018-eular.5630

\section{AB0660 1 THE ROLE OF ANTI-NEUTROPHIL CYTOPLASMIC AUTOANTIBODY SPECIFICITY FOR MPO OR PR3 IN PHENOTYPE OF ANCA ASSOCIATED VASCULITIS: KNOWING THE AUTOIMMUNITY IN LATIN AMERICA}

E. Calle $^{1}$, M. Calle ${ }^{2}$, H.B. Cabrera ${ }^{3}$, D. Jaramillo-Arroyave ${ }^{1,4,5}$, A.L. VanegasGarcía $^{6,7}$, G. Vásquez-Duque ${ }^{1}$, M. Restrepo-Escobar ${ }^{1}$, L.A. González-Naranjo ${ }^{1}$, J. Hernández-Zapata ${ }^{1}$, C.H. Muñoz-Vahos ${ }^{1,5,7} .{ }^{1}$ Grupo de Reumatología Universidad de Antioquia, Medellín; ${ }^{2}$ Universidad CES, Medellin; ${ }^{3}$ Medicina Interna, Universidad de Antioquia; ${ }^{4}$ Universidad CES; ${ }^{5}$ IPS Universitaria Clínica León XIII, Medellín; ${ }^{6}$ Grupo de Reumatología Universidad de Antioquia, Medellin; ${ }^{7}$ Hospital Universitario San Vicente Fundación, Medellín, Colombia

Background: Antineutrophil cytoplasmic antibodies (ANCA) are present in up to $90 \%$ granulomatosis with polyangiitis, $80 \%$ microscopic polyangiitis and $70 \%$ eosinophilic granulomatosis with polyangiitis. MPO-ANCA has been associated with vasculitis limited to the kidney, chronic renal damage and less frequent gastrointestinal or respiratory tract involvement. PR3-ANCA are characterised by destructive lesions of the ears, nose and throat, alveolar haemorrhage, combination of upper and/or lower respiratory tract involvement with renal compromise and increased number of relapses. The frequency of pulmonary involvement is similar in both serotypes, and most ANCA associated vasculitis (AAV) patients are diagnosed between ages 50 and 70 years.

Objectives: To describe differences in clinical profiles of patients with AAV regarding ANCA specificity against MPO or PR3 in a Colombian based adult population

Methods: All medical records of patients with a diagnosis of AAV in two high complexity hospitals in Medellín, Colombia from January 1, 2014 to December 31, 2016 were reviewed. The clinical and demographic characteristics were abstracted and analysed with descriptive and inferential statistics in SPSS.22 Results: Of 59 cases of AAV, 44 were positive for MPO or PR3-ANCA with male predominance $(65.5 \%$ men vs $34.5 \%$ women) and similar age at diagnosis (47 years in MPO-ANCA vs 50 in PR3-ANCA). MPO-ANCA group had more fever and weight loss (34.8\% vs $20 \%$ ), arterial hypertension (34.5\% vs $26.7 \%$ ), hematuria (34.5\% vs $26.7 \%$ ), proteinuria ( $31 \%$ vs $26.7 \%$ ), creatinin higher than $5.6 \mathrm{mg} / \mathrm{dL}$ (20.7 vs $13.3 \%$ ), myalgias (13.8 vs $0 \%$ ) pachymeningitis $(7 \%$ vs $0 \%$ ) and skin compromise. PR3-ANCA patients had more arthralgias/arthritis (40\% vs $31 \%)$ escleritis (33\% vs $13.8 \%$ ), episcleritis (13.3\% vs $0 \%$ ) and uveítis (10\% vs $7 \%$ ). Conclusions: In this Latin American population ANCA specificity affected the phenotype of clinical disease. MPO-ANCA patients had more constitutional symptoms, renal and central nervous system compromise while PR3-ANCA patients showed more articular and ocular involvement.

\section{REFERENCES}

[1] Cornec D, et al. Nat Rev Rheumatol. 2016 Oct;12(10):570-9.

[2] Hilhorst M, et al. J Am Soc Nephrol. 2015 Oct;26(10):2314-27.

[3] Lionaki S, et al. Arthritis Rheum. 2012 Oct;64(10):3452-62.

[4] Savige J, et al. Best Pract Res Clin Rheumatol. 2005 Apr;19(2):263-76.

[5] Schirmer JH, et al. Arthritis Rheumatol. 2016 Dec;68(12):2953-2963.

Disclosure of Interest: None declared DOI: 10.1136/annrheumdis-2018-eular.7488

\section{AB0661 ASSESSMENT OF DAMAGE AND PROGNOSIS IN PATIENTS WITH ADULT IGA VASCULITIS: RETROSPECTIVE MULTICENTERED COHORT STUDY}

F. Alibaz-Oner ${ }^{1}$, A. Omma ${ }^{2}$, A. Sarı ${ }^{3}$, Ü. Gazel ${ }^{1}$, D. Üsküdar Cansu ${ }^{4}$, A. Yazıcı ${ }^{5}$, A. Cefle ${ }^{5}$, C. Bes ${ }^{6}$, Ö. Karadağ ${ }^{3}$, H. Direskeneli ${ }^{1}{ }^{1}$ Rheumatology, Marmara University, School of Medicine, istanbul; ${ }^{2}$ Rheumatology, Ankara Numune Research and Training Hospital; ${ }^{3}$ Rheumatology, Hacettepe University, School of Medicine, Ankara; ${ }^{4}$ Rheumatology, Osmangazi University, School of Medicine, Eskişehir, ${ }^{5}$ Rheumatology, Kocaeli University, School of Medicine, Kocaeli; ${ }^{6}$ Rheumatology, Bakırköy Sadi Konuk Research and Training Hospital, istanbul, Turkey

Objectives: IgA Vasculitis is a leukocytoclastic vasculitis involving small vessels with depositions of immune complexes containing $\lg \mathrm{A}$. IgA Vasculitis is a predominantly paediatric vasculitis. There is limited data for the prognosis of adult IgA Vasculitis, with also no damage assessment. In this study, we aimed to evaluate 